\title{
Evaluation of WRF model seasonal forecasts for tropical region of Singapore
}

\author{
J. Singh ${ }^{1}$, K. Yeo ${ }^{2}$, X. Liu ${ }^{1}$, R. Hosseini ${ }^{1}$, and J. R. Kalagnanam ${ }^{1,2}$ \\ ${ }^{1}$ IBM Research Singapore, 9 Changi Business Park Central 1, The IBM Place, 468048, Singapore \\ ${ }^{2}$ IBM Thomas J. Watson Research Center, 1101 Kitchawan Rd, Yorktown Heights, New York, NY 10598, USA
}

Correspondence to: J. Singh (jsingh@sg.ibm.com)

Received: 15 January 2015 - Revised: 2 April 2015 - Accepted: 9 April 2015 - Published: 27 April 2015

\begin{abstract}
The Weather and Research Forecast (WRF) model is evaluated for the monsoon and inter-monsoon seasons over the tropical region of Singapore. The model configuration, physical parameterizations and performance results are described in this paper. In addition to the ready-to-use data available with the WRF model, the model configuration includes high resolution MODIS land use (500 $\mathrm{m}$ horizontal resolution) and JPL-NASA sea surface temperature ( $1 \mathrm{~km}$ horizontal resolution) data. The model evaluation is performed against near surface observations for temperature, relative humidity, wind speed and direction, available from a dense network of weather monitoring stations across Singapore. It is found that the high resolution data sets bring significant improvement in the model forecasts. The results also indicate that the model forecasts are more accurate in the monsoon seasons compared to the inter-monsoon seasons.
\end{abstract}

The high resolution meteorological outputs from a numerical weather prediction (NWP) model provide valuable inputs to derive a variety of air quality models and other urban applications. In this context, we are customizing the community based WRF-ARW model for Singapore. Undoubtedly, a thorough evaluation of the model forecasts is an important exercise for better understanding of the performance of such models and applications.

The WRF model is a community based mesoscale NWP model supported and maintained by NCAR (Skamarock et al., 2008). The WRF model is in principle suitable for a broad spectrum of applications across scales ranging from meters to thousands of kilometers. The model consists of advanced numerical and data-assimilation techniques, multiple domain nesting capability, and numerous state-of-the-art physical parameterization schemes.

In this study, we investigate the performance of the WRF model over Singapore region during the monsoon and intermonsoon seasons. The usage of WRF model for a tropical city appears to be few, cf. Li et al. (2013) and He et al. (2013) for studies related to Singapore. Singapore is situ- ated at the southern tip of the Malay peninsula with surface area of $700 \mathrm{~km}^{2}$ and has a population of 6 million. There are two monsoon seasons: North-East (December-March) and South-West (June-September) monsoon each separated by a two months inter-monsoon period. The weather of Singapore is impacted by the coastal breezes and due to small and short lived convective processes that are frequent in tropics. Due to availability of the observations from a dense observation network, Singapore represents a suitable geography for performance evaluation of the WRF model.

In the following sections we describe the model configuration and performance results from our current WRF modeling framework.

\section{Model configuration}

The WRF-ARW model version 3.5 is used in this study (Skamarock et al., 2008). The model is configured with four twoway nested domains of 27-9-3-1 km horizontal resolution, shown in Fig. 1. The innermost domain encompasses Singapore and surrounding areas of Malaysia and Indonesia. A total number of 43 vertical sigma layers are used, with first 15 layers below $1 \mathrm{~km}$ to better resolve the boundary layer. 
Table 1. Comparison of simulated temperatures using $500 \mathrm{~m}$ and $1 \mathrm{~km}$ MODIS land use data against the observations. Observed mean temperature is $28.58^{\circ} \mathrm{C}$.

\begin{tabular}{lccccc}
\hline NObs. $=343$ & Mean & MB & MGE & RMSE & HR \\
\hline MODIS $1 \mathrm{~km}$ & 27.41 & -1.16 & 1.34 & 1.75 & 0.76 \\
MODIS 500 m & 27.57 & -1.00 & 1.16 & 1.56 & 0.81 \\
\hline
\end{tabular}

Table 2. Same as Table 1 but for relative humidity. Observed mean relative humidity is $75.98 \%$.

\begin{tabular}{lccccc}
\hline NObs.=335 & Mean & MB & MGE & RMSE & HR \\
\hline MODIS 1 km & 85.19 & 9.20 & 10.58 & 12.62 & 0.33 \\
MODIS 500 m & 82.70 & 6.71 & 8.64 & 10.73 & 0.45 \\
\hline
\end{tabular}

In improvement efforts the 500-m resolution land use data from MODIS (UMD scheme) for all the domains is ingested in the model. The dominant land use categories in this data are shown in Fig. 2. This data consists of fewer categories in comparison to the $1 \mathrm{~km}$ MODIS data, but have an updated representation of the urban category. This is useful as Singapore has seen a rapid urbanization and land reclaimation in the past few decades. Other static data sets used are SRTM $90 \mathrm{~m}$ terrain height, vegetation data from MODIS and variety of data included in the WRF model.

The initial and boundary conditions are derived from the NCEP's Global Forecast System (GFS) data with $0.5^{\circ} \times 0.5^{\circ}$ spatial and $3 \mathrm{~h}$ temporal resolution, respectively. Soil moisture and temperature are also initialized from the same GFS data. The sea surface temperature is initialized from JPLNASA with spatial resolution of $1 \mathrm{~km}$. No data-assimilation is carried out for the results presented in this paper.

The physical parameterization schemes selected for all the experiments are as follows: New Thompson scheme for microphysics, MM5 similarity for surface layer physics, Noah LSM for surface physics, Kain-Fritsch cumulus scheme in the first three domains, New Goddard scheme for long and short radiation and Yonsei University scheme for PBL.

\section{Model evaluation}

The WRF model performance is evaluated against near surface observations for temperature, relative humidity and wind field (both speed and direction). These observations are available from a dense network of monitoring stations across Singapore operated by the National Environment Agency Singapore, see Fig. 3 for layout of the stations. The observation data are available at 1 minute temporal resolution for all the fields. Whereas, the model gridded output frequency is 30 minutes. Thus, the observations are averaged over one hour for evaluation purpose. Moreover, we select the nearest grid point to the station's location for a point-wise comparison.

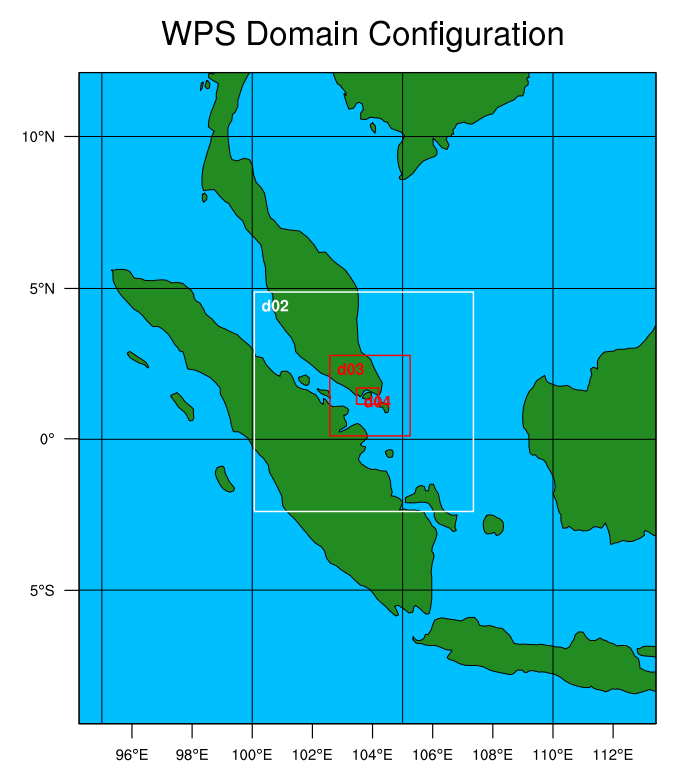

Figure 1. Nested computational domains for the WRF model setup. d04 encompasses Singapore and surrounding areas of Malaysia and Indonesia.
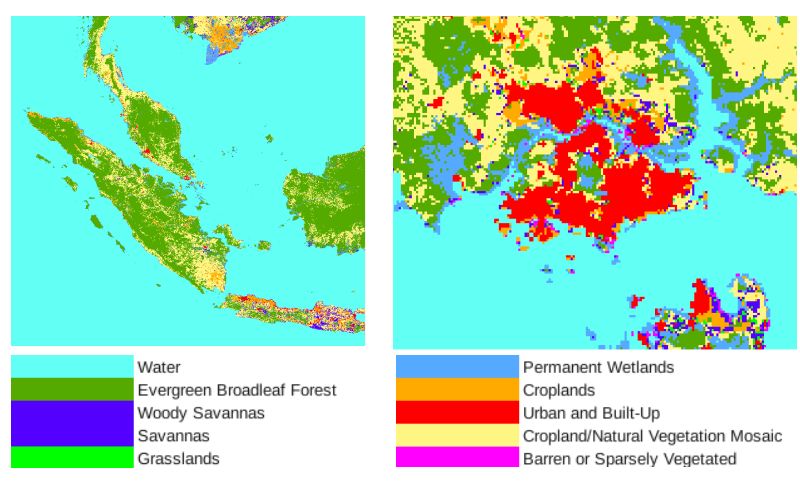

Figure 2. Dominant land use categories in the MODIS $500 \mathrm{~m}$ resolution data. The left and right figures correspond to the innermost (d01) and outermost (d04) computational domain, respectively.

For temperature and humidity the WRF simulated outputs at $2 \mathrm{~m}$ height are used and the wind components are compared with the model output at $10 \mathrm{~m}$ height.

The statistical measures considered are mean bias (MB), mean gross error (MGE), root mean square error (RMSE) and hit rate. The hit rate is defined as:

$$
\begin{aligned}
& \text { Hit Rate }(\mathrm{HR})=\frac{1}{N} \sum_{i=1}^{N} n_{i},
\end{aligned}
$$

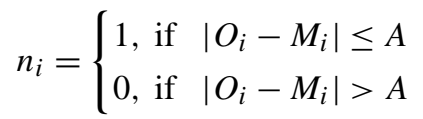

where $N$ is number of observations, $O_{i}$ and $M_{i}$ are the observed and model output values, respectively. The parameter $A$ corresponds to the desired accuracy. In this study $A$ 
Table 3. Same as Table 1 but for wind speed $\left(\mathrm{ms}^{-1}\right)$ and direction $\left(^{\circ}\right)$.

\begin{tabular}{lccccccc}
\hline & \multicolumn{3}{c}{ Speed $\left(\mathrm{ms}^{-1}\right)$} & & \multicolumn{3}{c}{ Direction $\left({ }^{\circ}\right)$} \\
\cline { 2 - 4 } \cline { 7 - 8 } NObs. $=375$ & MB & MGE & RMSE & & MB & MGE & RMSE \\
\hline MODIS 1 km & 0.64 & 1.03 & 1.34 & & -8.07 & 46.71 & 63.96 \\
MODIS 500 m & 0.41 & 0.91 & 1.19 & & -4.37 & 47.27 & 64.25 \\
\hline
\end{tabular}

Table 4. Comparison between the hourly average observed and simulated temperatures for a period of one week in each monsoon and inter-monsoon seasons.

\begin{tabular}{lccccccc}
\hline Period & NObs. & Mean (Obs.) & Mean & MB & MGE & RMSE & HR \\
\hline NE & 2005 & 27.35 & 26.76 & -0.58 & 0.82 & 1.06 & 0.94 \\
IM & 2059 & 28.40 & 28.42 & 0.01 & 1.33 & 1.67 & 0.76 \\
SW & 3035 & 28.15 & 28.41 & 0.25 & 1.13 & 1.48 & 0.83 \\
\hline
\end{tabular}

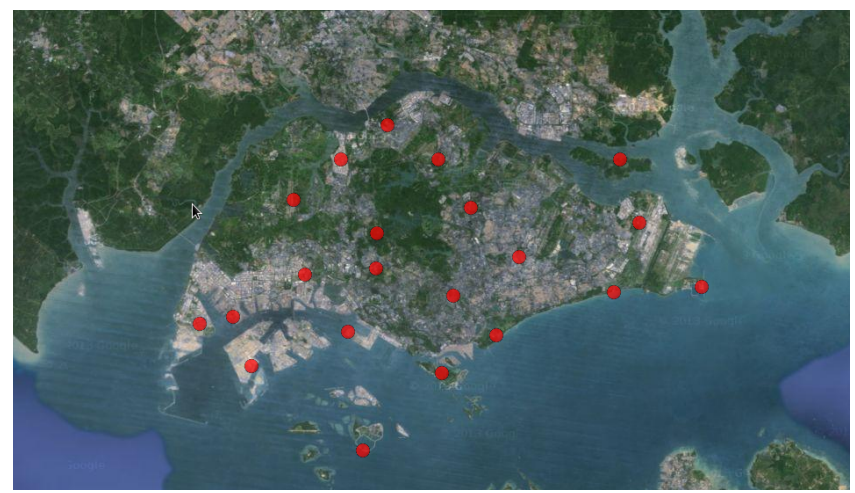

Figure 3. Weather monitoring station operated by the National Environment Agency of Singapore.

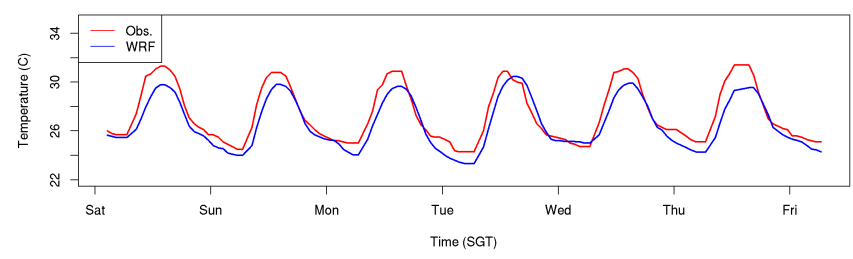

Figure 4. Time series plot of the hourly observed and model simulated temperatures at the Changi meteorological station during 2127 February 2014

is set to $2{ }^{\circ} \mathrm{C}$ for temperature and $7 \%$ for relative humidity. The negative/positive bias in wind direction implies that the model produced wind direction is anti-clockwise/clockwise with respect to the observed wind direction.

\subsection{Impact of high resolution land use data}

First, we evaluate the impact of ingesting high resolution land use data in the model. For this purpose we perform two simulations, one with MODIS $500 \mathrm{~m}$ data and second using

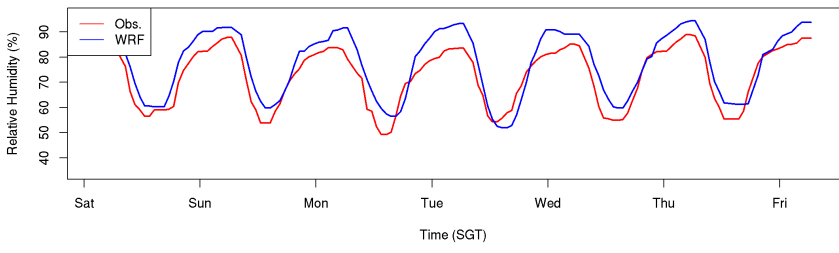

Figure 5. Same as Fig. 4 but for relative humidity.

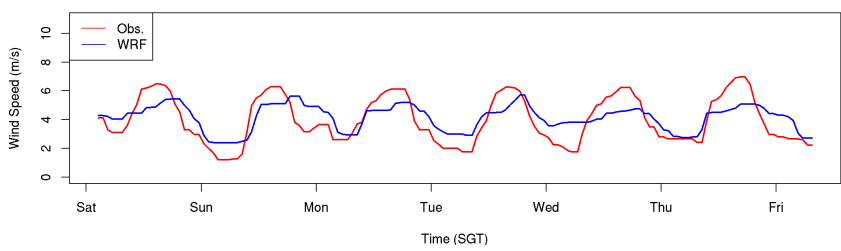

Figure 6. Same as Fig. 4 but for wind speed.

MODIS $1 \mathrm{~km}$ data $(1 \mathrm{~km}$ land use data is readily available with the WRF model). In both simulations the model is integrated for $36 \mathrm{~h}$ started at 12:00 UTC, 14 April 2014. The first $12 \mathrm{~h}$ of the simulations were discarded as the model spin-up time.

The results are summarized in Table 1 for temperature, in Table 2 for relative humidity and in Table 3 for wind field. As expected, the use of high resolution land use data results in a significant accuracy improvement.

\subsection{Evaluation for monsoon and inter-monsoon seasons}

To have a better understanding of the model performance, we evaluate the model results for different seasons prevailing in the region. A period of continuous seven days is chosen in each of the North-East (21-27 February 2014), the South-West (7-13 July 2014) and the Inter-Monsoon (2127 April 2014) seasons. The observation data are available from 21 stations during the South-West monsoon period and 
Table 5. Same as Table 4 but for relative humidity.

\begin{tabular}{lccccccc}
\hline Period & NObs. & Mean (Obs.) & Mean & MB & MGE & RMSE & HR \\
\hline NE & 2005 & 68.80 & 76.10 & 7.33 & 8.40 & 10.32 & 0.46 \\
IM & 2059 & 79.95 & 82.47 & 2.51 & 8.27 & 10.52 & 0.51 \\
SW & 3032 & 80.25 & 80.97 & 0.71 & 8.59 & 10.84 & 0.48 \\
\hline
\end{tabular}

Table 6. Same as Table 4 but for wind speed and direction.

\begin{tabular}{lcccccccc}
\hline & & \multicolumn{3}{c}{ Speed $\left(\mathrm{ms}^{-1}\right)$} & & \multicolumn{3}{c}{ Direction $\left({ }^{\circ}\right)$} \\
\cline { 3 - 5 } \cline { 7 - 9 } Period & NObs. & MB & MGE & RMSE & & MB & MGE & RMSE \\
\hline NE & 2086 & 1.16 & 1.51 & 1.81 & & 11.89 & 20.54 & 30.64 \\
IM & 2094 & 0.55 & 1.02 & 1.33 & & -2.58 & 72.42 & 88.41 \\
SW & 3035 & 1.26 & 1.50 & 1.85 & & 2.07 & 50.61 & 66.73 \\
\hline
\end{tabular}

from 16 stations during the North-East and Inter-Monsoon periods. For each day $36 \mathrm{~h}$ simulation starting at 12:00 UTC is performed and first $12 \mathrm{~h}$ are considered as spin-up time. The model set-up and configurations are same as described in Sect. 2.

The results for temperature for the periods mentioned above are summarized in Table 4 . It can be noticed that temperature is under (over) predicted in NE (SW) monsoon. The performance in IM period is less accurate than that of the monsoon periods.

The evaluation results for surface humidity for the three chosen periods are summarized in Table 5. The model overestimates relative humidity for all periods. However, the accuracy is slightly better in the IM period than in the monsoon periods.

The evaluation results for surface wind and direction are summarized in Table 6 . The most accurate results for wind are for NE monsoon season. This is because the wind in NE monsoon season is predominant in NE direction. In IM period the wind is slow but it is highly variable. This is also reflected in the model results. The wind direction in the IM period is less accurate compared to the monsoon periods.

The time series of the observations at the Changi airport station and the model simulated fields are plotted in Figs. 4, 5 and 6 for NE monsoon period. It can be observed that the WRF model is able to capture the diurnal variability.

\section{Conclusions}

In the present study, the WRF model is evaluated over the tropical region of Singapore. The model accuracy is significantly enhanced (approximately by $10 \%$ ) by the high resolution land use and sea surface temperature data. The over all performance of the model is evaluated for the monsoon and inter-monsoon seasons prevailing in the region. In each season the evaluation is performed for a period of one week. The results suggest that the WRF model with our current configuration and parameterizations performs better for the monsoon seasons. This can be attributed to the fact that the weather patterns are more dominant in the monsoon seasons in comparison to the inter-monsoon periods. Furthermore, our model performance is comparable to the results reported in the literature for other geographies. For inter-monsoon season, the model performs reasonably well for temperature and relative humidity. However, the wind direction, due to high variability in inter-monsoon season, has significant absolute errors though its biases are small. It can be mentioned that wind direction is an important input for simulating the pollutant dispersion phenomena in an urban area. The results presented in this paper would hopefully serve as an indication or benchmark for WRF studies in other tropical regions.

The current model configuration is operated in an operational setting to generate $24 \mathrm{~h}$ forecast to derive the air quality models. An advanced Urban Canopy Model is planned for the future.

\section{References}

He, S., Raghavan, S. V., Nguyen, N. S., and Liong, S.-Y.: Ensemble rainfall forecasting with numerical weather prediction and radar-based nowcasting models, Hydrol. Process., 27, 1560$1571,2013$.

Li, X.-X., Koh, T.-Y., Entekhabi, D., Roth, M., Panda, J., and Norford, L. K.: A multi-resolution ensemble 125 study of a tropical urban environment and its interactions with the background regional atmosphere, J. Geophys. Res.-Atmos., 118, 9804-9818, 2013.

Skamarock, W., Klemp, J., Dudhia, J., Gill, D., Barker, D., Duda, M., Huang, X., Wang, W., and Powers, J.: A Description of the Advanced Research WRF Version 3 (2008) NCAR Technical Note, Boulder, CO, 2008. 